\title{
Preface
}

\author{
D V Kudryashov ${ }^{1,2}$, E S Kozlova ${ }^{1,2}$, Ye V Goshin ${ }^{1}$ \\ ${ }^{1}$ Samara National Research University, Moskovskoe Shosse 34, Samara, Russia, 443086 \\ ${ }^{2}$ Image Processing Systems Institute of the RAS - Branch of the Federal Scientific Research \\ Centre "Crystallography and Photonics" of Russian Academy of Sciences, \\ Molodogvardeyskaya str. 151, Samara, Russia, 443001
}

This volume contains the papers presented at the session "Data Science" within the V International Conference on Information Technology and Nanotechnology (ITNT-2019).

The conference was held in Samara, Russia, during May 21-24, 2019 (itnt-conf.org). The conference is a forum for leading researchers from all over the world aimed to discuss the latest advances in the basic and applied research in the field of Information Technology and Nanotechnology. It is also aimed to attract young people to advanced scientific research and share the latest trends in training and research programs for future ITNT specialists [1].

In addition to the session "Data Science", ITNT-2019 also included three other sessions: "Computer Optics and Nanophotonics", "Image Processing and Earth Remote Sensing" and "Mathematical Modeling of Physico-Technical Processes and Systems". The whole forum brought together more than 450 scientists from United Kindom, Japan, Switzerland, Iran, Poland, Bulgaria, Finland, China, Kazakhstan and Russia, as well as representatives of global high-tech corporations, developers of modern electronics - Huawei, Nvidia, Intel, and Azimuth Photonics, and more than 60 cities in the world. 436 talks enabled discussion on a wide range of topics.

The topics of the session "Data Science" were grouped into the following key directions:

- Data Mining (Big data, Systems and platforms, Methods);

- Machine Learning (Neural networks, Statistical methods, Feature-based classification, Applications);

- Security, Cryptography (Cryptosystems design and analysis, Mathematical and algorithmic aspects, Efficient implementations of algorithms, Network security);

- High Performance Computing (Parallel programming models and languages, Highperformance implementations, Complex systems simulation).

This year we have received 188 submissions addressed to "Data Science". Each submission was carefully reviewed by the Program Committee members and the reviewers. Based on the reviews, we accepted 140 papers for the presentation at the conference (60 oral and 80 poster reports) and selected 69 papers for publication in this volume.

We thank all the participants of ITNT-2019 for excellent presentations and discussions, and we wish to see all of them at our future events.

\section{Conference Organizers}

- Samara National Research University, Samara, Russia

- Image Processing Systems Institute of the RAS - Branch of the Federal Scientific Research Centre "Crystallography and Photonics" of Russian Academy of Sciences, Samara, Russia

\section{Program Committee Chair}

- Viktor Soifer, Samara National Research University

\section{Organizing Committee Chair}

- Vladimir Bogatyrev, Samara National Research University 


\section{Vice-chairs}

- Nikolay Kazanskiy, Image Processing Systems Institute of the RAS

- Vladislav Sergeyev, Samara National Research University

- Alexander Kupriyanov, Samara National Research University

\section{Compilers of the volume}

- Vladimir Fursov, Samara National Research University

- Yegor Goshin, Samara National Research University

\section{Issuing editor}

- Denis Kudryashov, Samara National Research University

The conference was financially supported by the Ministry of Science and Higher Education of the Russian Federation.

Copyright (C) 2019 for the individual papers by the papers' authors. Copying permitted only for private and academic purposes. This volume is published and copyrighted by its editors.

\section{Reference}

[1] Savelyev D A 2017 Computer Optics 41(5) 775-785 DOI: 10.18287/2412-6179-2017-41-5-775785 